\title{
Trauma and seronegative spondyloarthropathy: rapid joint destruction in peripheral arthritis triggered by physical injury
}

\author{
IGNAZIO OLIVIERI, ${ }^{1}$ SANDRA GHERARDI, ${ }^{1}$ CHIARA BINI, ${ }^{1}$ \\ DONATELLA TRIPPI, ${ }^{2}$ MARIA LAURA CIOMPI, ${ }^{1}$ AND \\ GI A M PIERO PASERO ${ }^{1}$
}

From the ${ }^{I}$ Rheumatic Disease Unit of the Institute of Medical Pathology I and the ${ }^{2}$ Institute of Radiology, University of Pisa, Pisa, Italy

SUMMARY Two B27 positive patients developed peripheral arthritis immediately after a significant musculoskeletal injury. Unlike previously reported peripheral arthritis precipitated by trauma in B27 positive subjects the arthritis was rapidly destructive.

Key words: ankylosing spondylitis, trauma, HLA-B27 antigen.

The role of trauma in the initiation of seronegative spondyloarthropathy has been considered in various reports in the last few years. ${ }^{1-4}$

Although physical injury does not appear to determine spinal involvement in ankylosing spondylitis but brings it to the patient's attention, probably because of the consequent immobilisation, ${ }^{1}$ there is evidence that trauma may influence the onset in B27 positive subjects of a peripheral arthritis predominantly involving the injured joints. ${ }^{2-4}$

The present paper describes two more cases of peripheral arthritis triggered by trauma in B27 positive subjects. Unlike previous reports the arthritis was rapidly destructive.

\section{Case reports}

\section{CASE 1}

A 13 year old girl was well until 26 April 1986 when she fell and struck her right hip while running in an obstacle race. $x$ Rays of the hips were normal except for a sclerosis of both acetabular roofs, which was ascribed to scoliosis (Fig. 1a).

The following day the patient had a sore throat and a high temperature. Three days later she developed arthritis of the left elbow, the right hip, and both ankles and was admitted to hospital.

Investigations showed an erythrocyte sedimentation rate (ESR) (Westergren) of $112 \mathrm{~mm} / 1 \mathrm{st} \mathrm{h,C}$ reactive protein (CRP) $95 \mathrm{mg} / \mathrm{l}$ (normal $<5 \mathrm{mg} / \mathrm{l}$ ), white cell count $11.2 \times 10^{9} / 1$ with $70 \%$ polymorphonuclear leucocytes. The antistreptolysin $\mathrm{O}$ titre was

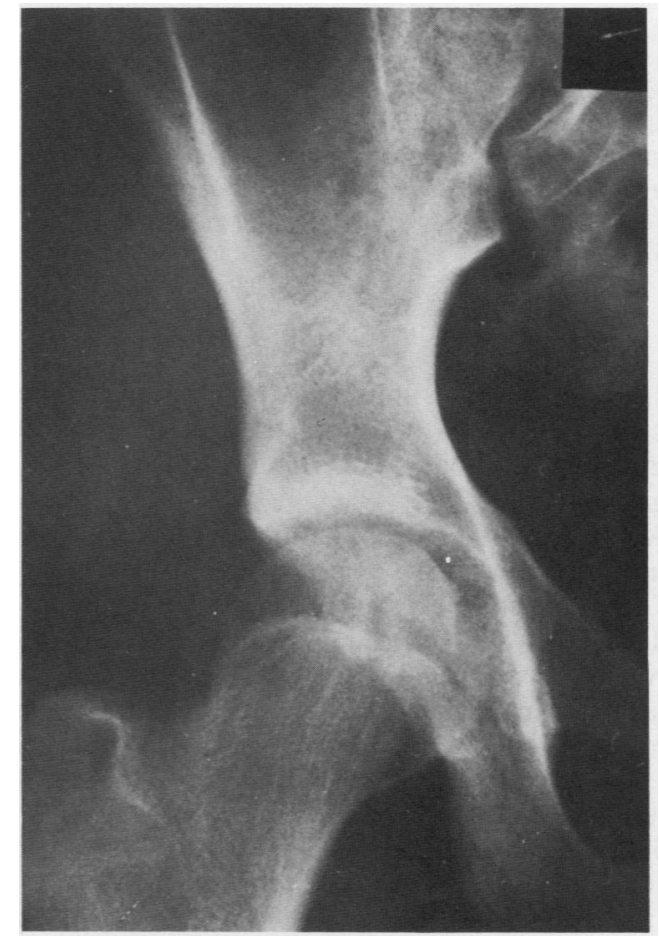

Fig. 1a 


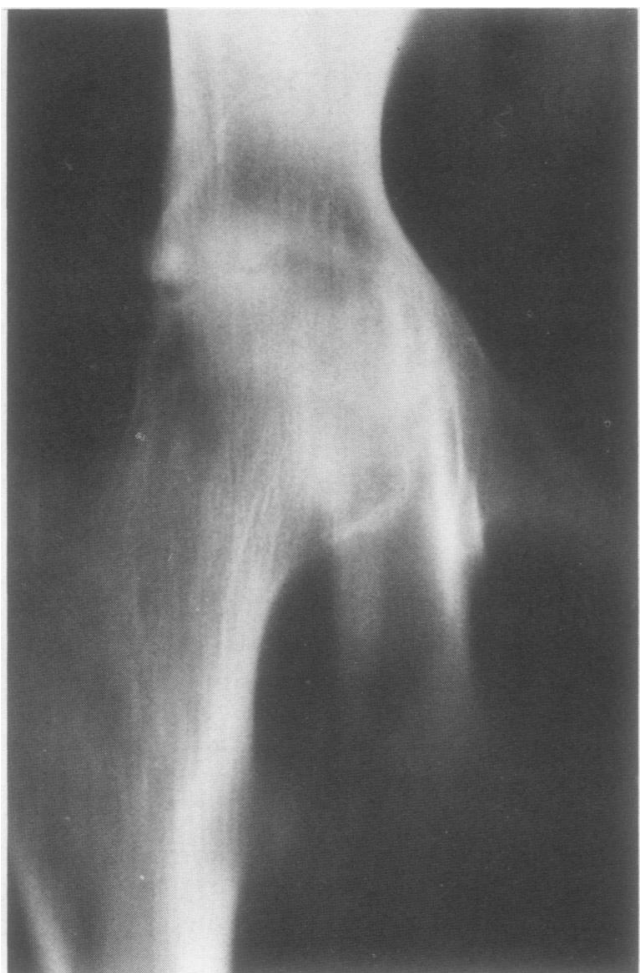

Fig. 1b

Fig. 1 Patient 1. Rapid progression of joint destruction of the right hip. (a) Radiograph taken on the day of trauma shows only a sclerosis of the acetabular roof. (b) Four months later severe concentric joint space narrowing, axial migration of femoral head, and erosions of the femoral head and the acetabular roof were visible (anteroposterior tomogram).

less than 200 Todd units and the streptozyme test was positive at a dilution of 1:664. Tests for antinuclear antibodies and rheumatoid factor were negative.

A cardiovascular examination and electrocardiogram were normal.

The patient was treated with penicillin (1.2 million units of benzathine penicillin intramuscularly), aspirin (initially $50 \mathrm{mg} / \mathrm{kg} /$ day divided into four doses, subsequently $25 \mathrm{mg} / \mathrm{kg} /$ day), and prednisone $(15 \mathrm{mg} /$ day for three weeks, then $10 \mathrm{mg} /$ day for three further weeks). Continual prophylaxis for rheumatic fever was begun.

Six weeks after its onset the arthritis subsided and prednisone was tapered to $5 \mathrm{mg} /$ day. At the beginning of August 1986 the ESR and CRP had returned to normal and prednisone was withdrawn. A total dose of $800 \mathrm{mg}$ of prednisone was received by the
patient.

In September 1986 because of recurrence of pairg in the right hip and progressive limitation of join mobility the patient was referred to us.

Physical examination showed tenderness and severe limitation in the range of movement of the right hip and pain on movement of the left elbow.

Laboratory examination showed an ESR of $2 \theta$ $\mathrm{mm} / 1 \mathrm{st} \mathrm{h}$, a CRP of $14 \mathrm{mg} / \mathrm{l}$, and negative tests for antinuclear antibodies and rheumatoid factor. HLAD typing was positive for the B27 antigen.

The past medical and family history were negative for HLA-B27 associated diseases.

Roentgenography showed severe concentric loss of the joint space and erosions of the right hip and reduction of the joint space of the left elbow. The lumbar spine and sacroiliac joints were normal ${ }_{c}^{-}$ Tomography showed more clearly erosions of bot许 the acetabular roof and the femoral head (Fig. 1b)

C A S E 2

In August 1986 a 25 year old woman was hit by $\overrightarrow{8}$ falling bookcase while she was writing in her office? She sustained multiple contusions. $x$ Rays of her right hip and femur taken the same day were normas (Fig. 2a).

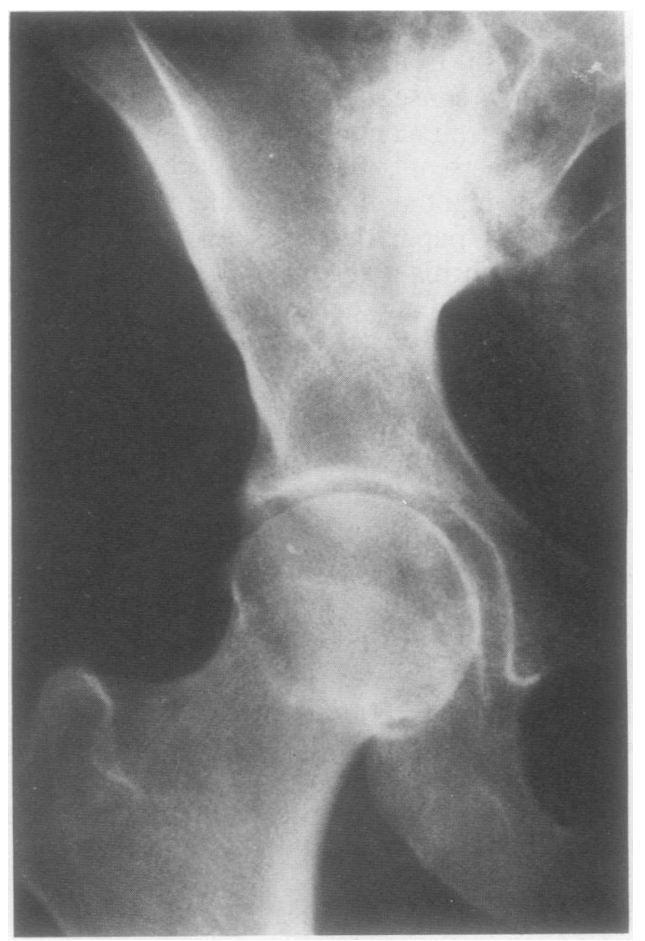

Fig. 2a 
During the following two months the pain became gradually more severe and disabling, so that the patient could not walk without a crutch. At the beginning of November 1986 she attended our unit.

Her past history showed that she had had three episodes of sciatic pain in the last four years and that she had felt continuous inflammatory low back pain and stiffness over the last year. There was no history of diarrhoea, urethritis, eye symptoms, or mucocutaneous lesions. The family history was negative for HLA-B27 associated diseases.

Physical examination of her right hip and lumbar spine was not possible because of the severity of hip pain. Chest expansion and cervical spine mobility were normal.

Laboratory evaluation showed an ESR of 45 $\mathrm{mm} / 1 \mathrm{st} \mathrm{h}$ and a CRP of $35 \mathrm{mg} / \mathrm{l}$. HLA typing was positive for the B27 antigen.

Roentgenography showed bilateral sacroiliitis,

already present in the radiogram obtained on the day of the trauma two months before, and a concentric reduction of the joint space and erosions of the right hip (Fig. 2b). The lumbar, cervical, and dorsal spine films were normal.

\section{Discussion}

Both these patients have a seronegative spondyloarthropathy. The first patient has a juvenile onset HLA-B27 associated asymmetric oligoarthritis. ${ }^{5-7}$ She lacked rheumatoid factor and antinuclear antibodies. The second patient has a bilateral sacroiliitis. She is B27 positive and has a four year history of sciatic pain and inflammatory low back pain and stiffness.

There seems little doubt about the close relation between the onset of peripheral arthritis and physical injury in these two patients. The first patient had arthritis of the left elbow, the right hip, and both ankles three days after trauma to the right hip. The second developed arthritis of the right hip immediately after an injury mainly involving the same joint.

The role of trauma in the onset of peripheral arthritis in seronegative spondyloarthropathy has been discussed in various recent reports. ${ }^{1-4}$ Wisniesky in 1984 reported the cases of two B27 positive patients who developed peripheral arthritis with features of Reiter's syndrome shortly after physical injury. ${ }^{2}$ Masson et al in 1985 described three more cases of Reiter's syndrome precipitated by trauma. ${ }^{3}$ All three patients were B27 positive and all three developed sacroiliitis in the months and years following the trauma. In their review of 58 cases of juvenile onset B27 positive spondyloarthropathy Jacobs $e t$ al found five children who had experienced trauma sufficiently severe to consult a physician before the onset of peripheral arthritis. ${ }^{4}$ Other cases of Reiter's syndrome influenced by trauma had previously been reported by Doury et al, ${ }^{8}$ Bernard et al, ${ }^{9}$ and Noer. ${ }^{10}$ HLA typing was not carried out in these cases.

It has been claimed that trauma also influences the onset of spinal involvement in ankylosing spondylitis. $^{3} 1112$ A recent study of Jacoby et al suggests that injury does not initiate ankylosing spondylitis but brings it to the patient's attention, probably due to enforced immobilisation. ${ }^{1}$

Unlike previously reported cases of peripheral arthritis triggered by trauma in B27 positive subjects, our two patients showed a rapid destructive process. Both patients showed concentric joint space narrowing and erosions in the injured joint only a few months after the trauma. The first patient also developed articular cartilage loss in the left elbow. The radiological appearance of the right hips 
in both patients corresponds to those of hip involvement in ankylosing spondylitis. ${ }^{13} 14$

Cases of post-traumatic chronic arthritis of the knee in psoriatic patients have been observed by Wright, ${ }^{15}$ and the case of a patient with psoriasis and post-traumatic erosive arthritis mainly of the injured joints has also been reported by Williams and Scott. ${ }^{16}$ HLA typing was not carried out in these cases.

The mechanisms involved in peripheral arthritis precipitated by trauma in patients affected by seronegative spondyloarthropathy are not clear. Wisniesky postulated that self antigens exposed after injury may lead in predisposed individuals to the development of an autoimmune reaction. ${ }^{2}$

\section{References}

1 Jacoby R K, Newell R L M, Hickling P. Ankylosing spondylitis and trauma: the medicolegal implications. A comparative study of patients with non-specific back pain. Ann Rheum Dis 1985; 44: $307-11$.

2 Wisniesky J J. Trauma and Reiter's syndrome: development of 'reactive arthropathy' in two patients following musculoskeletal injury. Ann Rheum Dis 1984; 43: 829-32.

3 Masson G, Thomas P, Bontoux D, Alcalay M. Influence of trauma on initiation of Reiter's syndrome and ankylosing spondylitis. Ann Rheum Dis 1985; 44: 860-1.

4 Jacobs J C, Berdon W E, Johnston A D. HLA-B27-associated spondyloarthritis and enthesopathy in childhood: clinical, pathologic, and radiographic observations in 58 patients. Pediatr 1982; 100: 521-8.

5 Joliat G, Ferro A, Jeannet M, Ott H. HLA-B27 antigen in diagnosis of atypical inflammatory arthropathy. Ann Rheum? Dis 1976; 35: 531-3.

6 Gester J C, Piccinin P. Enthesopathy of the heels in juvenile onset seronegative B-27 positive spondyloarthropathy. Rheumatol 1985; 12: 310-4.

7 Sambrook P, McGuigan L, Champion D, Edmonds J, Flemin\&్ఞ A, Portek I. Clinical features and followup study of HLA-B22 positive patients presenting with peripheral arthritis. J Rheuma? tol 1985; 12: 526-8.

8 Doury P, Pattin S, Ille H, Larroque P, Allard Ph. Syndrome de્ల Fiessinger-Leroy-Reiter avec traumatisme apparemment ins augural. Rev Rhum Mal Osteoartic 1974; 41: 55-7.

9 Bernard J G, Badrouillard R, Lucaes R, Feline A. Le syndrome de Fiessinger-Leroy-Reiter. 1. Etude clinique. 2. Etude épidé miologique et considérations étiologiques (à propos de 310 obs). Semin Hop Paris 1964; 48: 2623-9.

10 Noer H R. An 'experimental' epidemic of Reiter's syndrome JAMA 1966; 197: 693-8.

11 Forestier J, Jaqueline G, Rotes-Averol J. La spondylarthrite-

ankylosante. Paris: Masson, 1951: 226-7.
12 Louyot P, Gaucher A, Schneider R, Guillemin J. Spondylar气̆ thrite ankylosante d'origine traumatique. Rev Rhum Ma Osteoartic 1961; 28: 325-8.

13 Marks J S, Hardinge K. Clinical and radiographic features of spondylitic hip disease. Ann Rheum Dis 1979; 38: 332-6.

14 Dwosh I L, Resnick D, Becher M A. Hip involvement iro ankylosing spondylitis. Arthritis Rheum 1976; 19: 683-92.

15 Wright V. Psoriatic arthritis. In: Scott J T, ed. Copeman' textbook of rheumatic diseases. 5th ed. Edinburgh: Churchils Livingstone, 1978: 537-48.

16 Williams K A. Sott J T. Influence of trauma on the develop@ ment of chronic inflammatory polyarthritis. Ann Rheum Dip 1967; 26: 532-7. 